\title{
RESEARCH
}

Open Access

\section{Potential molecular mechanism of ACE gene at different time points in STEMI patients based on genome-wide microarray dataset}

\author{
Yao-Zong Guan ${ }^{1}$, Rui-Xing Yin ${ }^{1,2,3^{*}}$ (D, Peng-Fei Zheng ${ }^{1}$, Guo-Xiong Deng ${ }^{1}$, Chun-Xiao Liu ${ }^{1}$ and Bi-Liu Wei ${ }^{1}$
}

\begin{abstract}
Background: This study aimed to investigate the angiotensin converting enzyme (ACE) co-expression genes and their pathways involved in ST-segment elevation myocardial infarction (STEMI) at different time points.

Methods: The array data set of GSE59867 was examined for the ACE co-expression genes in peripheral blood samples from 111 patients with STEMI at four time points (admission, discharge, and 1 and 6 months after MI). Kyoto Encyclopedia of Genes and Genomes (KEGG) pathway enrichment, Gene Ontology (GO) annotation and protein-protein interaction (PPI) of the co-expression genes were determined using online analytical tools. The Cytoscape software was used to create modules and hub genes.

Results: The number of biological processes (BP), cellular components (CC) and molecular functions (MF) was 43, 22 and 24 at admission; 18, 19 and 11 at discharge; 30, 37 and 21 at 1 month after Ml; and 12, 19 and 14 at 6 months after $\mathrm{Ml}$; respectively. There were $6 \mathrm{BP}, 8 \mathrm{CC}$ and $4 \mathrm{MF}$ enriched at every time point. The co-expression genes were substantially enriched in 12, 5, 6 and 14 KEGG pathways at the four time points, respectively, but no KEGG pathway was found to be common in all time points. We identified 132 intersectional co-expression genes (90 positive and 42 negative) from the four time points and 17 BP, 13 CC, 11 MF and 7 KEGG pathways were enriched. In addition, the PPI network contained 129 nodes and 570 edges, and only 1 module was identified to be significantly enriched in just 1 BP (chromatin-mediated maintenance of transcription).

Conclusions: The results of the present study showed that the ACE co-expression genes and their pathways involved in STEMI were significantly different at four different time points. These findings may be helpful for further understanding the functions and roles of ACE in different stages of STEMI, and providing reference for the treatment of STEMI.
\end{abstract}

Keywords: Co-expression genes, ACE, Gene ontology annotation, Kyoto encyclopedia of genes and genomes (KEGG) pathway, ST-segment elevation myocardial infarction

\footnotetext{
*Correspondence: yinruixing@163.com

'Department of Cardiology, Institute of Cardiovascular Diseases, the First

Affiliated Hospital, Guangxi Medical University, 22 Shuangyong Road,

Nanning 530021, Guangxi, People's Republic of China

${ }^{2}$ Guangxi Key Laboratory Base of Precision Medicine in

Cardio-cerebrovascular Disease Control and Prevention, Nanning 530021,

Guangxi, People's Republic of China

Full list of author information is available at the end of the article
}

(c) The Author(s). 2019 Open Access This article is distributed under the terms of the Creative Commons Attribution 4.0 International License (http://creativecommons.org/licenses/by/4.0/), which permits unrestricted use, distribution, and reproduction in any medium, provided you give appropriate credit to the original author(s) and the source, provide a link to the Creative Commons license, and indicate if changes were made. The Creative Commons Public Domain Dedication waiver (http://creativecommons.org/publicdomain/zero/1.0/) applies to the data made available in this article, unless otherwise stated. 


\section{Introduction}

Coronary artery disease (CAD) is one of the leading causes of mortality among cardiovascular and cerebrovascular diseases, responsible for approximately 700,000 deaths in China [1, 2]. ST-segment elevation myocardial infarction (STEMI) is the most common cause of mortality in patients with CAD. Although with the establishment of coronary care units, improvements in medical therapy, and widespread use of early reperfusion therapy by primary percutaneous coronary intervention (PCI), the in-hospital mortality after STEMI has dramatically decreased to $\approx 5 \%$, cardiac deaths after discharge cannot be ignored [3].

Widely accepted risk factors for CAD include age, gender, hypertension, diabetes, smoking, dyslipidemia, family history, and genetic variation [4-6]. Current indicators of diagnosis and prognosis of myocardial infarction (MI) include electrocardiogram, troponin, myocardial enzyme, and left ventricular ejection fraction [7-9]. But the molecular mechanisms responsible for the development and progression of STEMI remain unclear. The angiotensin converting enzyme (ACE) is associated with vasoconstriction, inflammation, vascular remodeling, thrombosis, apoptosis, and eventual plaque rupture [10]. The present study aimed to utilize bioinformatics to identify genes co-expressed with $A C E$ genes and pathways associated with STEMI at different time points and to provide stage specific therapy for patients.

In the present study, the GSE59867 microarray expression dataset was extracted from the Gene Expression Omnibus (GEO) database, a global free-access repository of next-generation sequence functional genomic data sets and high-throughput microarray [11]. A genome-wide co-expression screening was performed by cor function in the $\mathrm{R}$ platform. All intersectional co-expression genes at the four time points were determined and depicted with Venn Diagrams. Gene Ontology (GO) and Kyoto Encyclopedia of Genes and Genomes (KEGG) analyses were used to define biological functions of the intersectional co-expression genes and the co-expressing genes at different time points. The GO and KEGG pathways were compared to separate the common genes as well as unique genes throughout the whole SETMI process and at specific time points. Finally, the Search Tool for the Retrieval of Interacting Genes (STRING) [12] was used to construct protein-protein interaction (PPI) network and to detect the hub genes.

\section{Materials and methods}

\section{Affymetrix microarray data}

The GSE59867 gene expression dataset was retrieved from GPL6244 Affymetrix Human Gene 1.0 ST Array platform from the GEO database (https://www.ncbi.nlm.
nih.gov/geo/query/acc.cgi?acc=GSE59867). The GSE59867 dataset contained 436 samples, out of which 390 samples from patients $(n=111)$ with STEMI at four time points (admission, discharge, 1 month after MI, and 6 months after MI) and 46 samples from patients $(n=46)$ with stable CAD and without a history of MI were included in the study [13]. The data extracted was normalized by limma package (http://www.bioconductor.org/packages/release/bioc/html/ limma.html) in the R platform, which is a software package providing powerful facilities for reading, normalizing and exploring microarray data $[14,15]$.

\section{Identification of ACE co-expression genes}

A genome-wide co-expression gene screening for $\mathrm{ACE}$ in patients with STEMI was performed by cor function in the $\mathrm{R}$ platform. The screening criteria were as follows: $P<0.05$, and | Pearson correlation coefficient $\mid \geq 0.2$. Then the online analytical tool Draw Venn Diagram (http://bioinformatics.psb.ugent.be/webtools/Venn/) was used to determine the intersectional co-expression genes at each time point.

\section{GO and KEGG pathway enrichment analyses}

GO and KEGG enrichment analyses of the co-expression genes were conducted separately on the Database for Annotation, Visualization and Integrated Discovery (DAVID) (version 6.8). Statistical significance was set at $P$-value < 0.05 . The results were visualized by the R-ggplot 2 package (version 3.5.3).

\section{Integration of the PPI network}

Interactions among the co-expression genes were evaluated using the STRING (version 10.5) database; a combined score of $>0.15$ was considered statistically significant interaction. In addition, the Cytoscape plugin cytoHubba (version 0.1 ), a package common used to identified the hub objects and sub-networks from complex interaction [14, 16], with the ranking methods of maximal clique centrality (MCC) was used to identify the top 10 hub genes.

\section{Results \\ Identification of ACE co-expression genes}

A total of 704 positively and 671 negatively co-expressed genes at admission, 350 positively and 489 negatively coexpressed genes at discharge, 550 positively and 539 negatively co-expressed genes at 1 month after MI, and 363 positively and 436 negatively co-expressed genes 6 months after MI were identified in this study. Figure 1 depicts a Venn diagram showing the 90 positively and 42 negatively co-expressed genes common across the time points. 


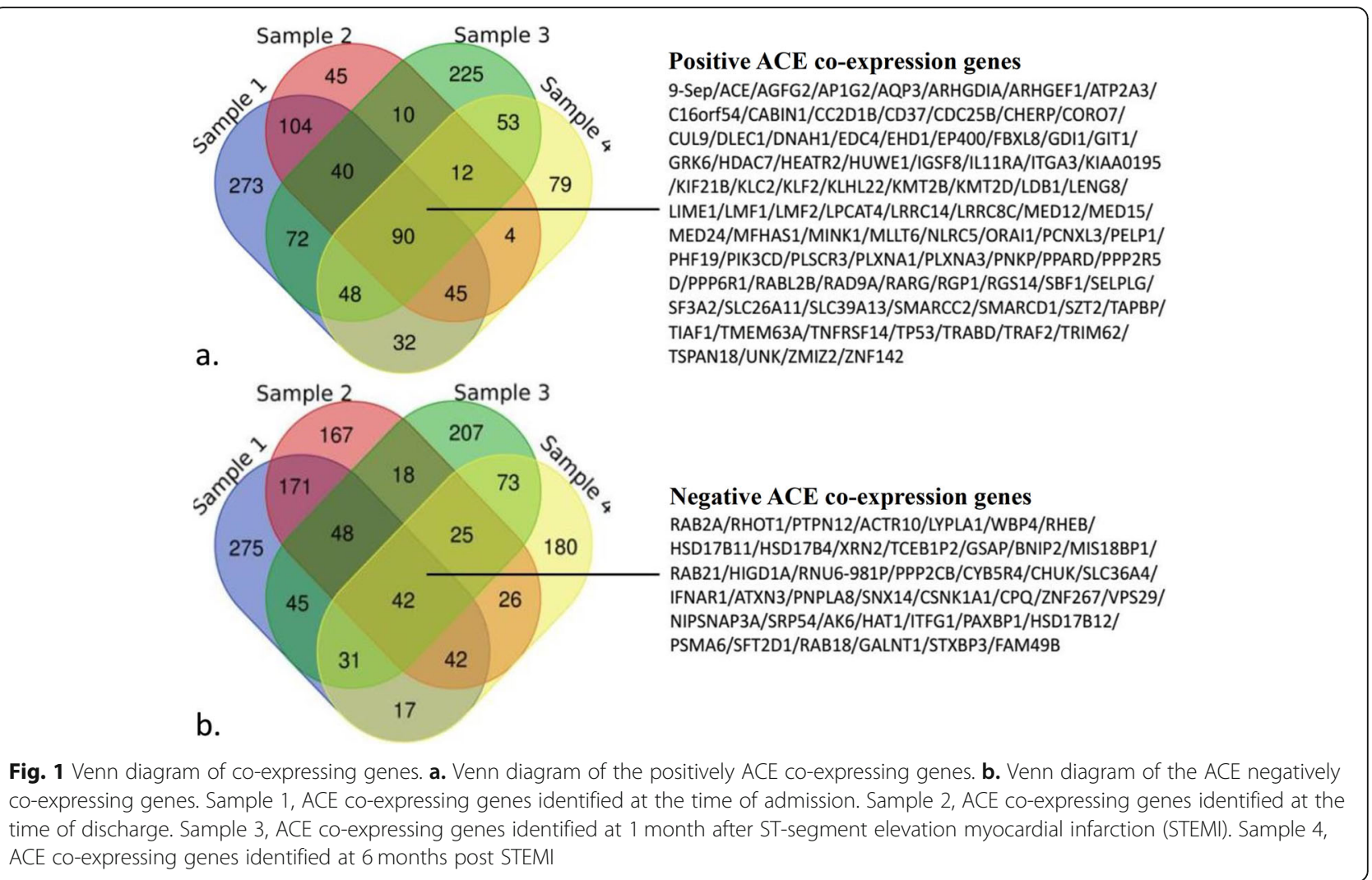

\section{Functional analysis of GO and KEGG pathways enrichment of co-expression genes}

GO function clustering revealed 43 biological processes (BP), 22 cellular components (CC), and 24 molecular functions (MF) at the time of admission; $18 \mathrm{BP}, 19 \mathrm{CC}$, and $11 \mathrm{MF}$ were identified at the time of discharge; $30 \mathrm{BP}$, $37 \mathrm{CC}$, and $21 \mathrm{MF}$ were identified at the time of 1 month after MI; and $12 \mathrm{BP}, 19 \mathrm{CC}$, and $14 \mathrm{MF}$ were identified at the time of 6 month after MI (Additional file 1: Tables S1S4). We selected the top seven BP, CC, and MF in descending order of count with $P<0.01$ at different time points for visualization (Fig. 2). Six BP (intracellular protein transport, positive regulation of transcription/DNA-templated, proteasome-mediated ubiquitin-dependent protein catabolic process, protein transport, small GTPase mediated signal transduction, Wnt signaling pathway), $4 \mathrm{MF}$ (chromatin binding, GTPase activator activity, GDP binding, protein binding) and $8 \mathrm{CC}$ (cytoplasm, cytosol, intracellular, nucleus, catalytic step 2 spliceosome, Golgi apparatus, membrane, nucleoplasm) were shared at all the time points. The analysis further identified $17 \mathrm{BP}, 13 \mathrm{CC}$ and $11 \mathrm{MF}$ as intersectional co-expression genes (Table 1 and Fig. 3).

The KEGG pathway analysis showed that genes coexpressing with ACE genes were substantially enriched in $12,5,6$ and 14 pathways at each time points, respectively (Additional file 1: Tables S5-S8) The intersectional co-expression genes mainly clustered into 7 pathways, including hepatitis $\mathrm{C}$, small cell lung cancer, apoptosis, thyroid hormone signaling pathway, sphingolipid signaling pathway, AMPK signaling pathway, and PI3K-Akt signaling. However, no KEGG pathway was found to be common across the four time points (Fig. 4).

\section{PPI network construction and hub gene identification}

A PPI network with 129 nodes and 570 edges was constructed to detect the interactions among the coexpressing genes with a combined score $>0.15$. With a cutoff criterion of MCODE score $>4$, only 1 module was identified, which was significantly enriched in just 1 biological process chromatin-mediated maintenance of transcription with co-expressing genes $K M T 2 D, K M T 2 B$ and SMARCD1 (Fig. 5).

\section{Discussion}

Over 80 million people have cardiovascular disease (CVD) in the United States, resulting in over 7 million revascularization procedures each year. Among them, STEMI accounts for a large proportion [17]. Not only the risk of death at the time of admission, but also the complications like dysfunction or rupture of papillary muscle, rupture of the heart, coronary stent thrombosis, malignant arrhythmia, post-infarction syndrome and heart failure give rise to the mortality $[10,18-20]$. The 


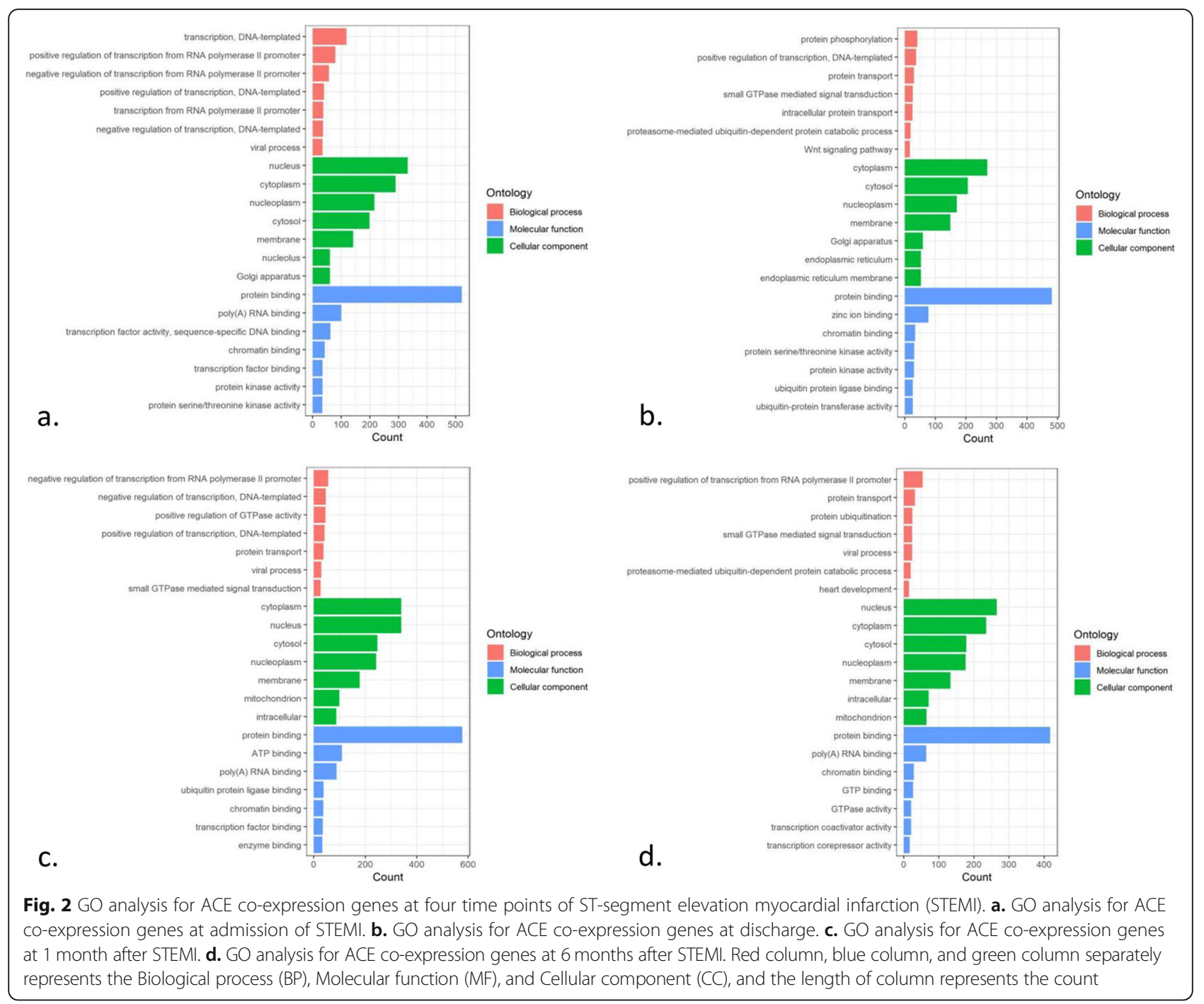

biological and regulatory mechanisms in the early or post-myocardial infarction stages remain understudied. The rapid development of microarray expression data and bioinformatics has offered improved methods and the tools to better understand complex diseases, like CVD, diabetes, and cancer. It is widely accepted that renin-angiotensin-aldosterone system (RAAS) is activated in myocardial ischemia and heart failure [21]. The ACE localized mainly in the endothelium and smooth muscle, promotes the conversion of angiotensin II (Ang II, a potent vasoconstrictor and growth factor) from angiotensin I in the renin-angiotensin system (RAS), and degrades bradykinin. Ang II activates its receptor AT1, which in turn activates fibroblasts, promoting myocardial fibrosis and scar formation. Furthermore, Ang II destabilizes Kv4.3 messenger RNA, resulting in decrease of outward potassium and prolongation of action potential duration, finally induces arrhythmias and heart failure [22, 23]. Interestingly, previous studies suggested that $\mathrm{ACE}$ can regulate the immune-related cytokines, IL12 , tumor necrosis factor- $\alpha$ (TNF- $\alpha$ ) and nitric oxide (NO), but finally proved the effect was due to the activation of AT1 by Ang II [24, 25]. A previous report by Tham et al showed that Ang II could regulate inflammation by down-regulated the PPAR receptors [25]. Thus, ACE involves in many mechanisms of physiology and pathophysiology with its central role in production of Ang II, chronic over-expression of tissue ACE causes over-production of Ang II. At the same time, decrease in bradykinin reduces the vasodilatory, profibrinolytic, antioxidant and antiapoptotic effects [26]. In the past decades, ACE inhibitors have been well received clinically with remarkable success based on their powerful effect on decreasing the production of Ang II [27]. In the present study, we identified genes co-expressed with $A C E$, and their GO enrichments and KEGG pathways at four time points of the STEMI. The analysis also identified the intersectional co-expression genes in all the time 
Table $1 \mathrm{GO}$ analysis for intersectional ACE co-expression genes

\begin{tabular}{|c|c|c|c|c|c|}
\hline Category & ID & Description & Count & $\begin{array}{l}P- \\
\text { Value }\end{array}$ & Gene ID \\
\hline BP & $\begin{array}{l}\text { GO: } \\
0007264\end{array}$ & $\begin{array}{l}\text { small GTPase } \\
\text { mediated signal } \\
\text { transduction }\end{array}$ & $8 / 200$ & $\begin{array}{l}1.77 \mathrm{E}- \\
03\end{array}$ & $\begin{array}{l}\text { RAB2A/GDI1/ } \\
\text { RAB18/MFHAS1/ } \\
\text { RHOT1/RHEB/ } \\
\text { RAB21/RABL2B }\end{array}$ \\
\hline BP & $\begin{array}{l}\text { GO: } \\
0050771\end{array}$ & $\begin{array}{l}\text { negative } \\
\text { regulation of } \\
\text { axonogenesis }\end{array}$ & $3 / 200$ & $\begin{array}{l}7.74 \mathrm{E}- \\
03\end{array}$ & $\begin{array}{l}\text { GDI1/ARHGEF1/ } \\
\text { ARHGDIA }\end{array}$ \\
\hline $\mathrm{BP}$ & $\begin{array}{l}\text { GO: } \\
0030334\end{array}$ & $\begin{array}{l}\text { regulation of } \\
\text { cell migration }\end{array}$ & $4 / 200$ & $\begin{array}{l}1.53 \mathrm{E}- \\
02\end{array}$ & $\begin{array}{l}\text { PLXNA3/ } \\
\text { PLXNA1/LDB1/ } \\
\text { MINK1 }\end{array}$ \\
\hline $\mathrm{BP}$ & $\begin{array}{l}\text { GO: } \\
0046677\end{array}$ & $\begin{array}{l}\text { response to } \\
\text { antibiotic }\end{array}$ & $3 / 200$ & $\begin{array}{l}2.12 \mathrm{E}- \\
02\end{array}$ & $\begin{array}{l}\text { CYB5R4/PPP2CB/ } \\
\text { TP53 }\end{array}$ \\
\hline BP & $\begin{array}{l}\text { GO: } \\
0015031\end{array}$ & $\begin{array}{l}\text { protein } \\
\text { transport }\end{array}$ & $8 / 200$ & $\begin{array}{l}2.15 \mathrm{E}- \\
02\end{array}$ & $\begin{array}{l}\text { SFT2D1/RAB2A/ } \\
\text { VPS29/GDI1/ } \\
\text { RAB18/SNX14/ } \\
\text { CORO7/RAB21 }\end{array}$ \\
\hline BP & $\begin{array}{l}\text { GO: } \\
0006367\end{array}$ & $\begin{array}{l}\text { transcription } \\
\text { initiation from } \\
\text { RNA polymerase } \\
\text { II promoter }\end{array}$ & $5 / 200$ & $\begin{array}{l}2.24 \mathrm{E}- \\
02\end{array}$ & $\begin{array}{l}\text { PPARD/RARG/ } \\
\text { MED15/MED12/ } \\
\text { MED24 }\end{array}$ \\
\hline BP & $\begin{array}{l}\text { GO: } \\
0008277\end{array}$ & $\begin{array}{l}\text { regulation of G- } \\
\text { protein coupled } \\
\text { receptor protein } \\
\text { signaling } \\
\text { pathway }\end{array}$ & $3 / 200$ & $\begin{array}{l}3.06 \mathrm{E}- \\
02\end{array}$ & $\begin{array}{l}\text { GIT1/GRK6/ } \\
\text { RGS14 }\end{array}$ \\
\hline BP & $\begin{array}{l}\text { GO: } \\
0043549\end{array}$ & $\begin{array}{l}\text { regulation of } \\
\text { kinase activity }\end{array}$ & $2 / 200$ & $\begin{array}{l}3.46 \mathrm{E}- \\
02\end{array}$ & NLRC5/LDB1 \\
\hline BP & $\begin{array}{l}\text { GO: } \\
0014910\end{array}$ & $\begin{array}{l}\text { regulation of } \\
\text { smooth muscle } \\
\text { cell migration }\end{array}$ & $2 / 200$ & $\begin{array}{l}3.46 \mathrm{E}- \\
02\end{array}$ & ACE/PLXNA1 \\
\hline BP & $\begin{array}{l}\text { GO: } \\
0014842\end{array}$ & $\begin{array}{l}\text { regulation of } \\
\text { skeletal muscle } \\
\text { satellite cell } \\
\text { proliferation }\end{array}$ & $2 / 200$ & $\begin{array}{l}4.14 \mathrm{E}- \\
02\end{array}$ & PPARD/PAXBP1 \\
\hline BP & $\begin{array}{l}\text { GO: } \\
0046939\end{array}$ & $\begin{array}{l}\text { nucleotide } \\
\text { phosphorylation }\end{array}$ & $2 / 200$ & $\begin{array}{l}4.14 \mathrm{E}- \\
02\end{array}$ & PNKP/AK6 \\
\hline BP & $\begin{array}{l}\text { GO: } \\
2000288\end{array}$ & $\begin{array}{l}\text { positive } \\
\text { regulation of } \\
\text { myoblast } \\
\text { proliferation }\end{array}$ & $2 / 200$ & $\begin{array}{l}4.14 \mathrm{E}- \\
02\end{array}$ & PPARD/PAXBP1 \\
\hline BP & $\begin{array}{l}\text { GO: } \\
0016569\end{array}$ & $\begin{array}{l}\text { covalent } \\
\text { chromatin } \\
\text { modification }\end{array}$ & $4 / 200$ & $\begin{array}{l}4.54 \mathrm{E}- \\
02\end{array}$ & $\begin{array}{l}\text { PHF19/ } \\
\text { SMARCC2/ } \\
\text { SMARCD1/ } \\
\text { CABIN1 }\end{array}$ \\
\hline BP & $\begin{array}{l}\text { GO: } \\
0043547\end{array}$ & $\begin{array}{l}\text { positive } \\
\text { regulation of } \\
\text { GTPase activity }\end{array}$ & $9 / 200$ & $\begin{array}{l}4.58 \mathrm{E}- \\
02\end{array}$ & $\begin{array}{l}\text { GIT1/GDI1/ } \\
\text { ARHGEF1/SBF1/ } \\
\text { BNIP2/AGFG2/ } \\
\text { RGP1/ARHGDIA/ } \\
\text { RGS14 }\end{array}$ \\
\hline $\mathrm{BP}$ & $\begin{array}{l}\text { GO: } \\
0048841\end{array}$ & $\begin{array}{l}\text { regulation of } \\
\text { axon extension } \\
\text { involved in axon } \\
\text { guidance }\end{array}$ & $2 / 200$ & $\begin{array}{l}4.82 \mathrm{E}- \\
02\end{array}$ & PLXNA3/PLXNA1 \\
\hline BP & $\begin{array}{l}\text { GO: } \\
0019827\end{array}$ & $\begin{array}{l}\text { stem cell } \\
\text { population } \\
\text { maintenance }\end{array}$ & $3 / 200$ & $\begin{array}{l}4.82 \mathrm{E}- \\
02\end{array}$ & $\begin{array}{l}\text { PHF19/MED12/ } \\
\text { MED24 }\end{array}$ \\
\hline BP & $\begin{array}{l}\text { GO: } \\
0007266\end{array}$ & $\begin{array}{l}\text { Rho protein } \\
\text { signal }\end{array}$ & $3 / 200$ & $\begin{array}{l}4.82 \mathrm{E}- \\
02\end{array}$ & $\begin{array}{l}\text { ARHGEF1/ } \\
\text { ARHGDIA/CHUK }\end{array}$ \\
\hline
\end{tabular}

Table $1 \mathrm{GO}$ analysis for intersectional ACE co-expression genes (Continued)

\begin{tabular}{|c|c|c|c|c|c|}
\hline Category & ID & Description & Count & $\begin{array}{l}P- \\
\text { Value }\end{array}$ & Gene ID \\
\hline & & transduction & & & \\
\hline CC & $\begin{array}{l}\text { GO: } \\
0016020\end{array}$ & membrane & $\begin{array}{l}36 / \\
200\end{array}$ & $\begin{array}{l}6.08 \mathrm{E}- \\
07\end{array}$ & $\begin{array}{l}\text { ORAI1/PLXNA3/ } \\
\text { GALNT1/CHERP/ } \\
\text { AP1G2/AGFG2/ } \\
\text { LRRC8C/LMF2/ } \\
\text { EDC4/RGP1/ } \\
\text { KLC2/TAPBP/ } \\
\text { SFT2D1/ACE/ } \\
\text { FAM49B/PELP1/ } \\
\text { HSD17B4/EHD1/ } \\
\text { SELPLG/ } \\
\text { CSNK1A1/GIT1/ } \\
\text { MED12/CORO7/ } \\
\text { AK6/IL11RA/ } \\
\text { LPCAT4/PNKP/ } \\
\text { PNPLA8/IGSF8/ } \\
\text { CD37/MED15/ } \\
\text { HUWE1/GRK6/ } \\
\text { RHOT1/RHEB/ } \\
\text { XRN2 }\end{array}$ \\
\hline CC & $\begin{array}{l}\text { GO: } \\
0005789\end{array}$ & $\begin{array}{l}\text { endoplasmic } \\
\text { reticulum } \\
\text { membrane }\end{array}$ & $\begin{array}{l}15 / \\
200\end{array}$ & $\begin{array}{l}1.88 \mathrm{E}- \\
03\end{array}$ & $\begin{array}{l}\text { RAB2A/CYB5R4/ } \\
\text { GALNT1/LMF2/ } \\
\text { LRRC8C/ } \\
\text { HSD17B12/LMF1/ } \\
\text { LPCAT4/TAPBP/ } \\
\text { PNPLA8/ATXN3/ } \\
\text { RAB18/ATP2A3/ } \\
\text { RHEB/RAB21 }\end{array}$ \\
\hline CC & $\begin{array}{l}\text { GO: } \\
0005654\end{array}$ & nucleoplasm & $\begin{array}{l}32 / \\
200\end{array}$ & $\begin{array}{l}2.42 \mathrm{E}- \\
03\end{array}$ & $\begin{array}{l}\text { KMT2D/PPARD/ } \\
\text { PPP2R5D/KMT2B/ } \\
\text { HAT1/MED24/ } \\
\text { EDC4/WBP4/ } \\
\text { SLC26A11/PELP1/ } \\
\text { CC2D1B/CHUK/ } \\
\text { RARG/TP53/ } \\
\text { MED12/RAD9A/ } \\
\text { SF3A2/AK6/ } \\
\text { CDC25B/PNKP/ } \\
\text { ATXN3/PHF19/ } \\
\text { PSMA6/MED15/ } \\
\text { HUWE1/ZMIZ2/ } \\
\text { SMARCC2/ } \\
\text { CABIN1/ } \\
\text { MIS18BP1/EP400/ } \\
\text { XRN2/HDAC7 }\end{array}$ \\
\hline CC & $\begin{array}{l}\text { GO: } \\
0005829\end{array}$ & cytosol & $\begin{array}{l}36 / \\
200\end{array}$ & $\begin{array}{l}2.94 \mathrm{E}- \\
03\end{array}$ & $\begin{array}{l}\text { VPS29/ } \\
\text { HSD17B11/ } \\
\text { TRAF2/PPP2R5D/ } \\
\text { PPP6R1/ } \\
\text { NIPSNAP3A/ } \\
\text { EDC4/RGP1/ } \\
\text { KLC2/PAXBP1/ } \\
\text { NLRC5/PPP2CB/ } \\
\text { CHUK/ARHGDIA/ } \\
\text { CSNK1A1/GIT1/ } \\
\text { GDI1/SRP54/ } \\
\text { ARHGEF1/ } \\
\text { PIK3CD/TP53/ } \\
\text { MINK1/CORO7/ } \\
\text { STXBP3/LYPLA1/ } \\
\text { TRIM62/PTPN12/ } \\
\text { CDC25B/ATXN3/ } \\
\text { RAB18/PSMA6/ } \\
\text { HUWE1/BNIP2/ }\end{array}$ \\
\hline
\end{tabular}


Table $1 \mathrm{GO}$ analysis for intersectional ACE co-expression genes (Continued)

\begin{tabular}{|c|c|c|c|c|c|}
\hline Category & ID & Description & Count & $\begin{array}{l}P \text { - } \\
\text { Value }\end{array}$ & Gene ID \\
\hline & & & & & $\begin{array}{l}\text { FBXL8/RHOT1/ } \\
\text { RHEB }\end{array}$ \\
\hline CC & $\begin{array}{l}\text { GO: } \\
0043234\end{array}$ & protein complex & $9 / 200$ & $\begin{array}{l}6.55 \mathrm{E}- \\
03\end{array}$ & $\begin{array}{l}\text { GDI1/ORAI1/ } \\
\text { LDB1/SMARCC2/ } \\
\text { TP53/HAT1/ } \\
\text { RGP1/KLC2/ } \\
\text { HIGD1A }\end{array}$ \\
\hline CC & $\begin{array}{l}\text { GO: } \\
0000790\end{array}$ & $\begin{array}{l}\text { nuclear } \\
\text { chromatin }\end{array}$ & $6 / 200$ & $\begin{array}{l}9.67 \mathrm{E}- \\
03\end{array}$ & $\begin{array}{l}\text { PPARD/RARG/ } \\
\text { LDB1/SMARCC2/ } \\
\text { TP53/HAT1 }\end{array}$ \\
\hline CC & $\begin{array}{l}\text { GO: } \\
0043231\end{array}$ & $\begin{array}{l}\text { intracellular } \\
\text { membrane- } \\
\text { bounded } \\
\text { organelle }\end{array}$ & $\begin{array}{l}10 / \\
200\end{array}$ & $\begin{array}{l}1.27 \mathrm{E}- \\
02\end{array}$ & $\begin{array}{l}\text { HSD17B11/ } \\
\text { VPS29/PLXNA3/ } \\
\text { BNIP2/HAT1/ } \\
\text { EDC4/CC2D1B/ } \\
\text { HSD17B4/ } \\
\text { SLC26A11/CHUK }\end{array}$ \\
\hline CC & $\begin{array}{l}\text { GO: } \\
0016235\end{array}$ & aggresome & $3 / 200$ & $\begin{array}{l}2.05 \mathrm{E}- \\
02\end{array}$ & $\begin{array}{l}\text { GIT1/CABIN1/ } \\
\text { XRN2 }\end{array}$ \\
\hline CC & $\begin{array}{l}\text { GO: } \\
0016592\end{array}$ & $\begin{array}{l}\text { mediator } \\
\text { complex }\end{array}$ & $3 / 200$ & $\begin{array}{l}2.29 \mathrm{E}- \\
02\end{array}$ & $\begin{array}{l}\text { MED15/MED12/ } \\
\text { MED24 }\end{array}$ \\
\hline CC & $\begin{array}{l}\text { GO: } \\
0016363\end{array}$ & nuclear matrix & $4 / 200$ & $\begin{array}{l}2.74 \mathrm{E}- \\
02\end{array}$ & $\begin{array}{l}\text { ATXN3/PSMA6/ } \\
\text { TP53/HAT1 }\end{array}$ \\
\hline CC & $\begin{array}{l}\text { GO: } \\
0009898\end{array}$ & $\begin{array}{l}\text { cytoplasmic side } \\
\text { of plasma } \\
\text { membrane }\end{array}$ & $3 / 200$ & $\begin{array}{l}3.22 \mathrm{E}- \\
02\end{array}$ & $\begin{array}{l}\text { TRAF2/RAB21/ } \\
\text { CHUK }\end{array}$ \\
\hline CC & $\begin{array}{l}\text { GO: } \\
0000139\end{array}$ & $\begin{array}{l}\text { Golgi } \\
\text { membrane }\end{array}$ & $9 / 200$ & $\begin{array}{l}4.51 \mathrm{E}- \\
02\end{array}$ & $\begin{array}{l}\text { RAB2A/PNPLA8/ } \\
\text { GALNT1/AP1G2/ } \\
\text { PPP6R1/RHEB/ } \\
\text { CORO7/RGP1/ } \\
\text { TAPBP }\end{array}$ \\
\hline CC & $\begin{array}{l}\text { GO: } \\
0016607\end{array}$ & nuclear speck & $5 / 200$ & $\begin{array}{l}4.62 \mathrm{E}- \\
02\end{array}$ & $\begin{array}{l}\text { CSNK1A1/SRP54/ } \\
\text { SF3A2/WBP4/ } \\
\text { EP400 }\end{array}$ \\
\hline MF & $\begin{array}{l}\text { GO: } \\
0005515\end{array}$ & protein binding & $\begin{array}{l}84 / \\
200\end{array}$ & $\begin{array}{l}2.44 \mathrm{E}- \\
06\end{array}$ & $\begin{array}{l}\text { PPARD/PLXNA3/ } \\
\text { CHERP/AP1G2/ } \\
\text { PPP2R5D/ } \\
\text { LRRC8C/ } \\
\text { NIPSNAP3A/ } \\
\text { EDC4/MED24/ } \\
\text { RGP1/WBP4/ } \\
\text { TAPBP/NLRC5/ } \\
\text { FAM49B/ } \\
\text { MFHAS1/CUL9/ } \\
\text { SMARCD1/ } \\
\text { KLHL22/CHUK/ } \\
\text { RAB21/RARG/ } \\
\text { ARHGEF1/LDB1/ } \\
\text { PIK3CD/TP53/ } \\
\text { MED12/MINK1/ } \\
\text { CORO7/ } \\
\text { TNFRSF14/ } \\
\text { STXBP3/RAD9A/ } \\
\text { LENG8/IFNAR1/ } \\
\text { PNKP/CD37/ } \\
\text { IGSF8/PSMA6/ } \\
\text { HUWE1/MED15/ } \\
\text { RAB18/FBXL8/ } \\
\text { BNIP2/ZMIZ2/ } \\
\text { EP400/XRN2/ } \\
\text { VPS29/TRAF2/ }\end{array}$ \\
\hline
\end{tabular}

Table $1 \mathrm{GO}$ analysis for intersectional ACE co-expression genes (Continued)

\begin{tabular}{|c|c|c|c|c|c|}
\hline Category & ID & Description & Count & $\begin{array}{l}P \text { - } \\
\text { Value }\end{array}$ & Gene ID \\
\hline & & & & & $\begin{array}{l}\text { KMT2D/ORAl1/ } \\
\text { SLC39A13/LMF2/ } \\
\text { KMT2B/ } \\
\text { HSD17B12/ } \\
\text { PPP6R1/HAT1/ } \\
\text { KLC2/PELP1// } \\
\text { PPP2CB/CC2D1B/ } \\
\text { MLLT6/EHD1/ } \\
\text { SELPLG/ } \\
\text { ARHGDIA/ } \\
\text { CSNK1A1/GIT1/ } \\
\text { RAB2A/GDI1/ } \\
\text { SRP54/ITGA3/ } \\
\text { SF3A2/AK6/ } \\
\text { PTPN12/RGS14/ } \\
\text { CDC25B/ATXN3/ } \\
\text { PHF19/ } \\
\text { SMARCC2/ } \\
\text { PLSCR3/RHOT1/ } \\
\text { GRK6/MIS18BP1/ } \\
\text { KLF2/HDAC7/ } \\
\text { ACTR10 }\end{array}$ \\
\hline MF & $\begin{array}{l}\text { GO: } \\
0005525\end{array}$ & GTP binding & $9 / 200$ & $\begin{array}{l}4.29 \mathrm{E}- \\
03\end{array}$ & $\begin{array}{l}\text { RAB2A/SRP54/ } \\
\text { RAB18/MFHAS1/ } \\
\text { RHOT1/RHEB/ } \\
\text { EHD1/RAB21/ } \\
\text { RABL2B }\end{array}$ \\
\hline MF & $\begin{array}{l}\text { GO: } \\
0003924\end{array}$ & GTPase activity & $7 / 200$ & $\begin{array}{l}4.91 \mathrm{E}- \\
03\end{array}$ & $\begin{array}{l}\text { RAB2A/SRP54/ } \\
\text { RAB18/RHOT1/ } \\
\text { RHEB/RAB21/ } \\
\text { RABL2B }\end{array}$ \\
\hline MF & $\begin{array}{l}\text { GO: } \\
0019003\end{array}$ & GDP binding & $4 / 200$ & $\begin{array}{l}5.65 \mathrm{E}- \\
03\end{array}$ & $\begin{array}{l}\text { RAB2A/SRP54/ } \\
\text { RAB18/RAB21 }\end{array}$ \\
\hline MF & $\begin{array}{l}\text { GO: } \\
0005096\end{array}$ & $\begin{array}{l}\text { GTPase activator } \\
\text { activity }\end{array}$ & $7 / 200$ & $\begin{array}{l}1.12 \mathrm{E}- \\
02\end{array}$ & $\begin{array}{l}\text { GIT1/GDI1/ } \\
\text { ARHGEF1/BNIP2/ } \\
\text { AGFG2/ } \\
\text { ARHGDIA/RGS14 }\end{array}$ \\
\hline MF & $\begin{array}{l}\text { GO: } \\
0003682\end{array}$ & $\begin{array}{l}\text { chromatin } \\
\text { binding }\end{array}$ & $8 / 200$ & $\begin{array}{l}1.61 \mathrm{E}- \\
02\end{array}$ & $\begin{array}{l}\text { PELP1/LDB1/ } \\
\text { SMARCC2/ } \\
\text { SMARCD1/TP53/ } \\
\text { MED12/ EP400/ } \\
\text { HDAC7 }\end{array}$ \\
\hline MF & $\begin{array}{l}\text { GO: } \\
0001104\end{array}$ & $\begin{array}{l}\text { RNA polymerase } \\
\text { II transcription } \\
\text { cofactor activity, }\end{array}$ & $3 / 200$ & $\begin{array}{l}2.41 \mathrm{E}- \\
02\end{array}$ & $\begin{array}{l}\text { MED15/MED12/ } \\
\text { MED24 }\end{array}$ \\
\hline MF & $\begin{array}{l}\text { GO: } \\
0004721\end{array}$ & $\begin{array}{l}\text { phosphoprotein } \\
\text { phosphatase } \\
\text { activity }\end{array}$ & $3 / 200$ & $\begin{array}{l}3.65 \mathrm{E}- \\
02\end{array}$ & $\begin{array}{l}\text { PPP2CB/PTPN12/ } \\
\text { CDC25B }\end{array}$ \\
\hline MF & $\begin{array}{l}\text { GO: } \\
0019901\end{array}$ & $\begin{array}{l}\text { protein kinase } \\
\text { binding }\end{array}$ & $7 / 200$ & $\begin{array}{l}4.07 \mathrm{E}- \\
02\end{array}$ & $\begin{array}{l}\text { TRAF2/TP53/ } \\
\text { RHEB/RAD9A/ } \\
\text { RGS14/HDAC7/ } \\
\text { CDC25B }\end{array}$ \\
\hline
\end{tabular}

points to determine the GO enrichments and KEGG pathways throughout the stages of $\mathrm{MI}$ and the recovery process, and the unique GO enrichments and KEGG pathways at different time points of STEMI.

Identification of co-expressed genes is the cornerstone of $\mathrm{BP}, \mathrm{CC}, \mathrm{MF}$ and enrichment pathway analysis. Using 


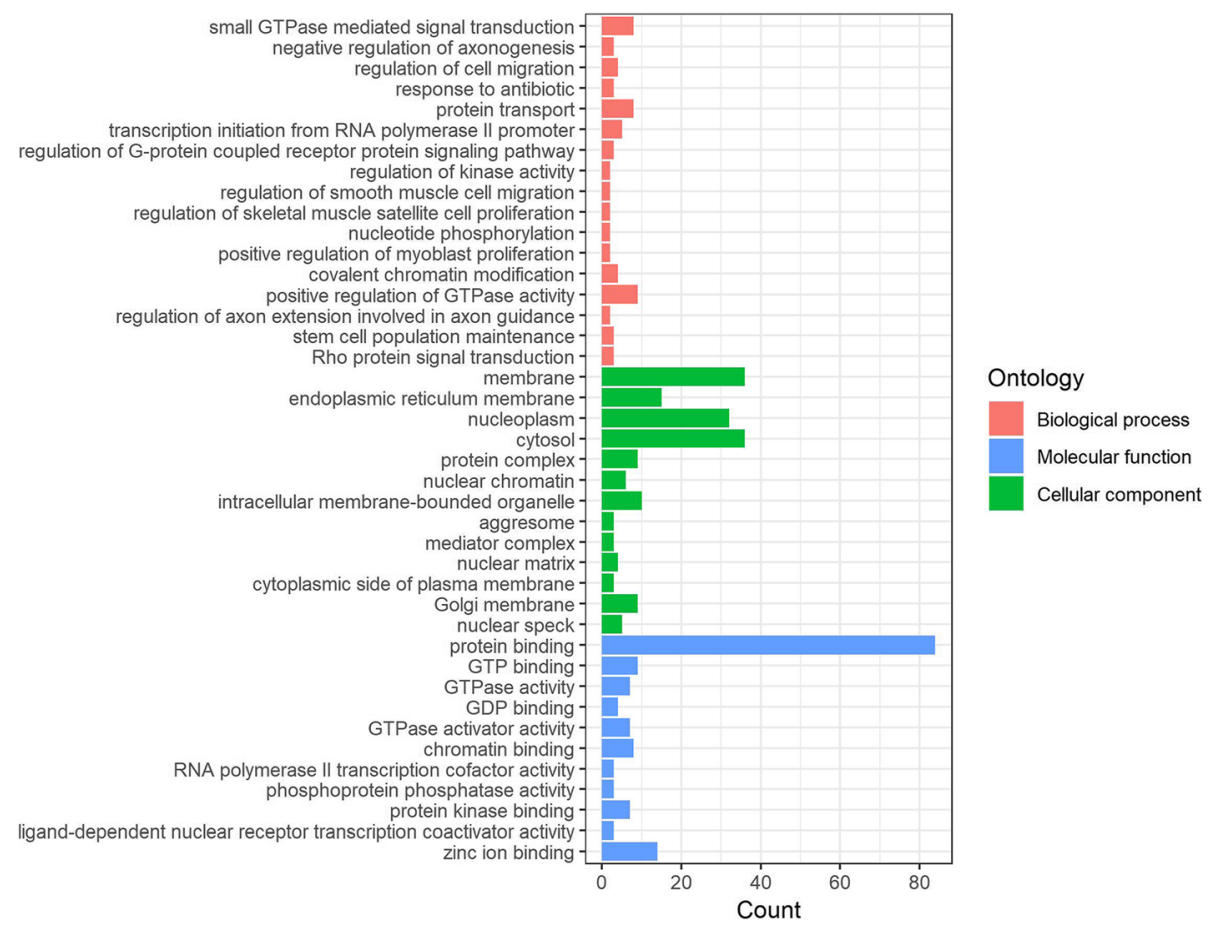

Fig. $3 \mathrm{GO}$ analysis for intersectional ACE co-expression genes. Red column, blue column, and green column separately represents the Biological process (BP), Molecular function (MF), and Cellular component (CC), and the length of column represents the count

the Venn diagram, we identified 90 positively and 42 negatively co-expressing genes of the intersection of the four time points. The gene SELPLG, also called PSGL-1 was reported to be expressed at a high level in CD4+ TCells from patients with plaque rupture or intracoronary thrombus. It was also implicated in plaque instability in acute coronary syndrome (ACS) [28-30]. The KLF2 gene is a vascular homeostasis-associated molecular marker, which regulates the expression of a wide range of antiinflammatory, antioxidant, and antithrombotic genes in endothelial cells. Compared with patients with stable angina pectoris or normal controls, KLF2 expression in dendritic cells in patients with ACS was found to be reduced [31, 32]. Some previous study reported that FBW7 tumor suppressor induces endothelial differentiation by modulating the NF1/RAS axis. The $\mathrm{SCF}^{\mathrm{FBW}-\mathrm{RBX} / \mathrm{SAG}}$ (an ubiquitin ligase) activates RAS by promoting the degradation of NF1, and KLF2 acts as physiological substrate of FBW7. These results suggest that expression of KLF2 may indirectly affect the activity of ACE [33]. P53, the known tumor suppressor with characteristic of promoting apoptosis, was also reported to be associated with CAD [34-36]. What's more, the TNF signals can activate both renin and p53 by inhibiting phosphoinositide 3-kinases (PI3Ks) via JNK pathway [37, 38]. This may be one of the reasons for the positive correlation between the expression of ACE and P53. In our study, PSGL-1, KLF2 and P53 were among the positively co-expression genes of $A C E$ at every time points of STEMI, that is to say, high-expressed ACE is accompanied by high-expressed PSGL-1, KLF2 and P53. ACE mainly mediates the production of Ang II, promoting the activation of inflammation and apoptosis, co-expressed of it, PSGL-1 and $p 53$ may promote the inflammation and apoptosis, while $K L F 2$ plays the opposite role involved in the progression of STEMI. Whether ACE positively regulates these genes directly or through a feedback way is still the direction of our next step would focus on.

On the other hand, the PNPLA1-PNPLA9 are members of the PNPLA family, playing different biological functions. Among them, PNPLA2 is a key enzyme in the hydrolysis of stored triglycerides (TG), while PNPLA8 is a myocardial phospholipase, maintaining mitochondrial integrity [39]. The GALNT family with lipase and transacylase properties appeared to play major roles in the regulation of lipid metabolism [40]. In addition, data from Pulido et al [41] supported that $R A B 18$ is a common mediator of lipolysis and lipogenesis, and suggested that the endoplasmic reticulum is the link that connected $R A B 18$ action on these two processes. In the current study, we showed that the PNPLA, RAB18 and GALNT1 were the negatively co-expressed genes of ACE at all the time points, in other words, increased ACE expression was accompanied by decreased expression of these genes. In the development of STEMI, decreased expression of PNPLA2 may decrease hydrolysis of stored 


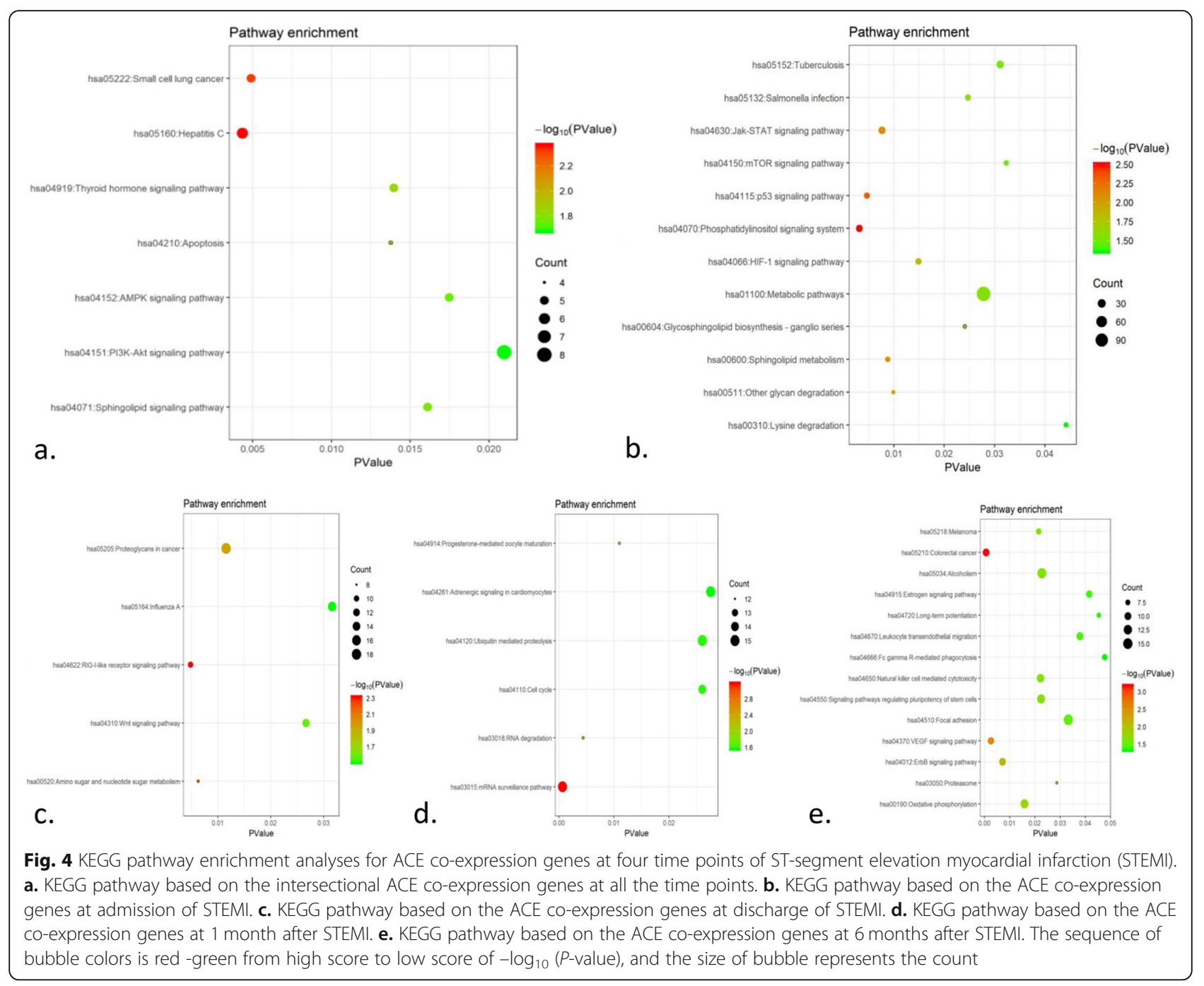

TG to reduce the serum TG levels, while decreased expression of PNPLA8 may weaken mitochondrial integrity and reduce energy supply. In context of $R A B 18$, its decrease expression may be partly responsible for the changes in serum lipid levels. Passos-Silva et al showed that Ang (1-7) regulated the metabolism by increasing glucose uptake and lipolysis, and decreasing insulin resistance and dyslipidemia [42]. The expression of ACE may affect the expression of Ang (1-7), in turn affects the metabolism. Therefore, the expression of these genes may be negatively regulated by ACE or negative feedback from ACE, but it needs further researches to confirm.

GO and KEGG pathways enrichment analysis revealed several shared pathways across the time points. The Wnt signaling plays dominant roles in the pathology of CVDs including inflammation, fibrosis, intracellular cholesterol accumulation and heart failure following MI, mobilization and proliferation of cells in the endothelium and epicardium in an infarcted heart [43-46]. The endothelium is directly involved in heart disease, peripheral vascular disease, diabetes, insulin resistance, stroke, venous thrombosis, chronic kidney failure, metastasis, tumor growth, and severe viral infectious diseases directly [47]. After injury, migration, proliferation of endothelial cells, and reendothelialization of the vessel is essential in the restoring of blood vessel health. Many of these processes are regulated, and are dependent on small GTPases $[17,48]$. Thus, regulation of the Wnt signaling pathway or promotion of endothelialization might attenuate cardiovascular events after STEMI and that studying the regulation of the small GTPase could be an interesting starting point.

Using the MCODE, we identified only 1 module enriched and just 1 biological process- chromatinmediated maintenance of transcription from the PPI network. In addition, 10 hub genes were identified using CytoHubba with a high level of connectivity - TP53 (p53), KMT2B (MLL4), KMT2D, EP400 (p400), HDAC7, RAB2A, PIK3CD (PI3K), MED12 (OPA1), HUWE1, and 


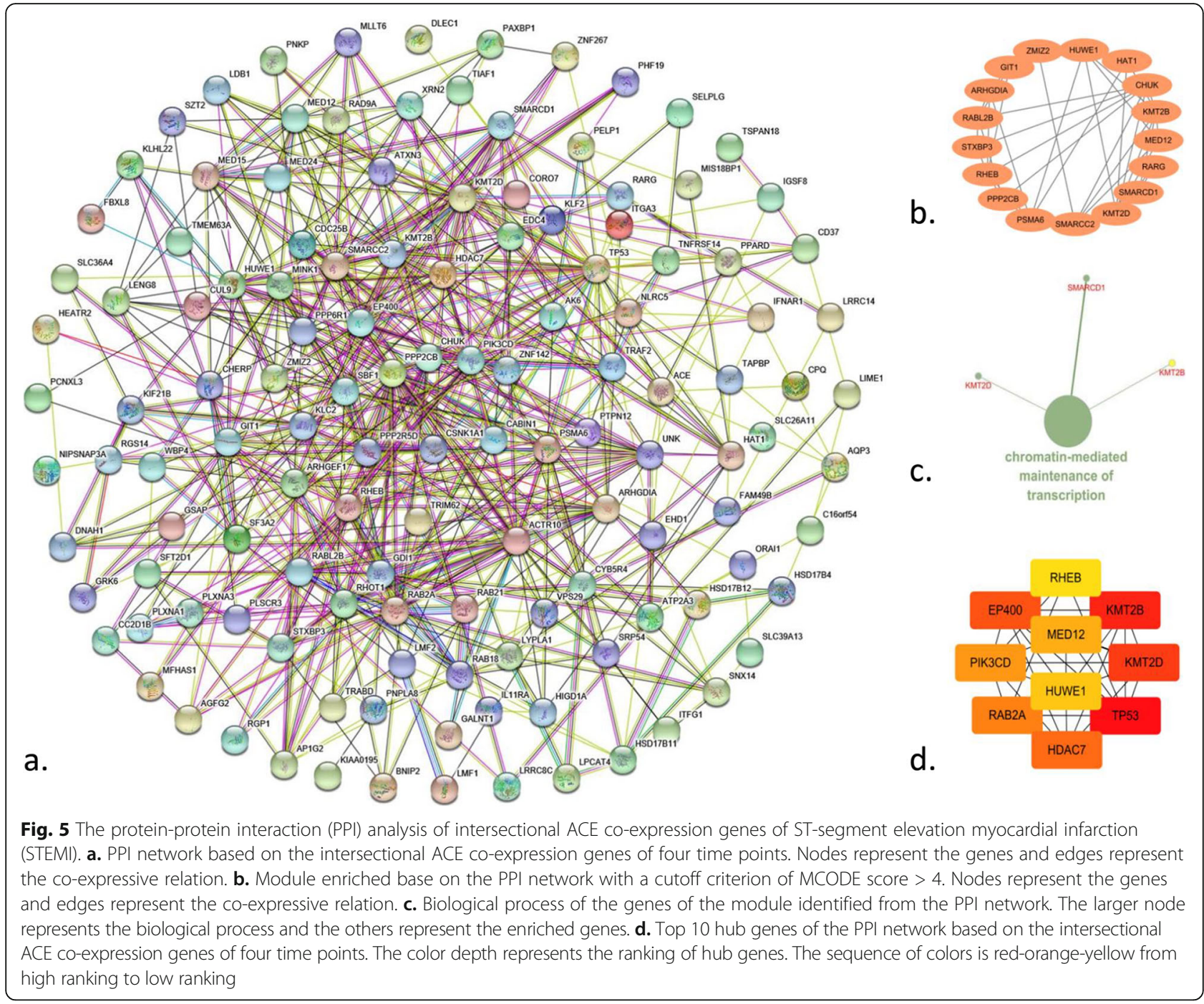

RHEB (mTORC1). In the context of cellular immunity and apoptosis, Rahnamoun et al. [49] reported a novel mechanism in which the mutant TP53 and KMT2B cooperated to regulate aberrant enhancer activity and tumor-promoting gene expression in response to chronic immune signaling. The EP400 E1A-associated protein, which mediates H2A.Z incorporation at specific promoters, plays a major role in cell fate decisions; it promotes cell cycle progression and inhibits apoptosis or senescence [50]. Decrease in MED12, which is important for maintaining normal cristae structure and function, resulted in increased apoptosis and mitochondrial fragmentation, and thereby reduction in energy supplement [51]. Li et al. [52] reported that, compared to non - CAD controls, HDAC7 mRNA expression level was markedly lower in monocytes of CAD patients. That means these genes either participate in or regulate immune response and apoptosis. In our study, p53, KMT2B, KMT2D, EP400, and HDAC7 were positively co-expressed with $\mathrm{ACE}$, and increase in their expression may inhibit apoptosis and decrease mitochondrial energy metabolism. As both immune cells and apoptosis play important roles in the development of CAD, these genes could be promising targets for intervention for the treatment of CAD.

For blood glucose and lipid metabolism, previous studies give us the point that $R A B 2 A$ knockdown inhibited glucose-stimulated insulin secretion, what's more, it also regulated both initiation and termination of autophagy in mammalian cells $[53,54]$. Silencing the ligases, HUWE1 and NEDD4-1, increased the cholesterol export from cells [55]. In the context of thrombosis and endothelial injury, the $\mathrm{p} 110 \delta$ plays a partial role in aggregation and spreading of platelet, and PI3K-Akt is cardio-protective in ischemic pre-conditioning $[56,57]$. The mechanistic target of rapamycin complex 1 (mTORC1), one of the major pathways associated with cellular energy sensing, mediates vascular endothelial function through modulation of ROS signaling [58]. These findings indicated that the hub genes 
RAB2A, PI3K, HUWE1 and $m T O R C 1$ are the regulators of glucose metabolism, lipid metabolism, platelet and endothelial function. Our results suggested that these genes were negatively co-expressed with $\mathrm{ACE}$, and decrease in their expression may reduce insulin secretion, increases serum cholesterol levels or result in vascular endothelial dysfunction and are closely related to the occurrence and development of CAD. Although to date clear evidence that ACE directly or indirectly regulates their expression is still lack, in depth understanding of the regulation of these genes may provide effective strategies for the recovery of patients with STEMI.

Our study aims to explore the mechanism of STEMI at different times from the perspective of positively or negatively co-expressed genes with ACE, which is different from the previous approach of analysis based on upregulation and down-regulation of genes. However, there are some limitations of our research. Firstly, the results of our study cannot definitively confirm whether ACE could directly or indirectly regulates these genes. Secondly, the data from GSE59867 does not provide the factors associated with CAD like age, gender and blood lipid levels for correction. Finally, some potential factors that we have not clear may interfere with the end results.

\section{Conclusions}

In this study, genome-wide co-expressing genes based on the GSE59867 dataset were used to identify the functions and mechanism of ACE gene at different time points of STEMI. We found that the ACE co-expression genes and their pathways involved in STEMI were significantly different at four different time points. These findings may help to better understand the functions and roles of ACE and co-expression genes in STEMI, and provide reference for future treatment strategies. However, further studies are required to validate the role of these co-expressing genes and pathways involved in different stages of STEMI.

\section{Supplementary information}

Supplementary information accompanies this paper at https://doi.org/10. 1186/s12944-019-1131-3.

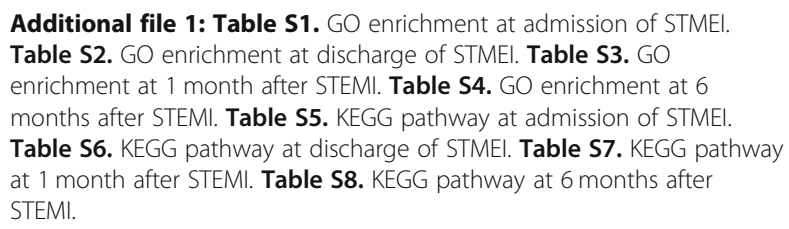

\section{Abbreviations}

ACE: Angiotensin converting enzyme; BP: Biological processes;

CAD: Coronary artery disease; CC: Cellular components; CVD: Cardiovascular disease; ER: Endoplasmic reticulum; GEO: Gene Expression Omnibus;

GO: Gene Ontology annotation; KEGG: Kyoto Encyclopedia of Genes and
Genomes pathway enrichment analyses; MCODE: Molecular Complex Detection; MF: Molecular functions; PCl: percutaneous coronary intervention; PPI: Protein-protein interaction; RAS: Renin-angiotensin system; STEMI: STsegment elevation myocardial infarction; TG: triglycerides

\section{Acknowledgements}

Not applicable.

\section{Authors' contributions}

YZG conceived the study, participated in the design, performed the statistical analyses, and drafted the manuscript. RXY conceived the study, participated in the design and helped to draft the manuscript. PFZ and GXD contributed in formal analysis. CXL and BLW helped to draft the manuscript. All authors read and approved the final manuscript.

\section{Funding}

This study was supported by the National Natural Science Foundation of China (No. 81460169). The funders had no role in the design of the study; in the collection, analyses, or interpretation of data; in the writing of the manuscript, or in the decision to publish the results.

\section{Availability of data and materials}

The datasets used and/or analyzed during the current study are available from the Gene Expression Omnibus repository (https://www.ncbi.nlm.nih. gov/geo/query/acc.cgi?acc=GSE59867).

Ethics approval and consent to participate

Not applicable.

Consent for publication

Not applicable.

\section{Competing interests}

The authors declare that they have no competing interests.

\section{Author details}

${ }^{1}$ Department of Cardiology, Institute of Cardiovascular Diseases, the First Affiliated Hospital, Guangxi Medical University, 22 Shuangyong Road, Nanning 530021, Guangxi, People's Republic of China. ${ }^{2}$ Guangxi Key Laboratory Base of Precision Medicine in Cardio-cerebrovascular Disease Control and Prevention, Nanning 530021, Guangxi, People's Republic of China. ${ }^{3}$ Guangxi Clinical Research Center for Cardio-cerebrovascular Diseases, Nanning 530021, Guangxi, People's Republic of China.

Received: 17 July 2019 Accepted: 3 October 2019

Published online: 23 October 2019

\section{References}

1. Wang F, Xu CQ, He Q, Cai JP, Li XC, Wang D, et al. Genome-wide association identifies a susceptibility locus for coronary artery disease in the Chinese Han population. Nat Genet. 2011:43(4):345-9.

2. Smith SC, Jackson R, Pearson TA, Fuster V, Yusuf S, Faergeman O, et al. Principles for national and regional guidelines on cardiovascular disease prevention. Circulation. 2004;109(25):3112-21.

3. Keeley EC, Boura JA, Grines CL. Primary angioplasty versus intravenous thrombolytic therapy for acute myocardial infarction: a quantitative review of 23 randomised trials. Lancet. 2003;361(9351):13-20.

4. Banerjee A, Lim CC, Silver LE, Welch SJ, Banning AP, Rothwell PM. Familial history of stroke is associated with acute coronary syndromes in women. Circ Cardiovasc Genet. 2011:4(1):9-15.

5. Yamada Y, Matsui K, Takeuchi I, Fujimaki T. Association of genetic variants with coronary artery disease and ischemic stroke in a longitudinal population-based genetic epidemiological study. Biomed Rep. 2015;3(3):413-9.

6. Deloukas P, Kanoni S, Willenborg C, Farrall M, Assimes TL, Thompson JR, et al. Large-scale association analysis identifies new risk loci for coronary artery disease. Nat Genet. 2012;45(1):25-33.

7. Eyuboglu M, Akdeniz B. Left ventricular ejection fraction in the prognosis of acute coronary syndromes. Int J Cardiol. 2017;234:137. 
8. Lim WY, Thevarajah TM, Goh BT, Khor SM. Paper microfluidic device for early diagnosis and prognosis of acute myocardial infarction via quantitative multiplex cardiac biomarker detection. Biosens Bioelectron. 2019;128:176-85.

9. Tung R, Zimetbaum P. Chapter 11 - use of the electrocardiogram in acute myocardial infarction. In: Jeremias A, Brown DL, editors. Cardiac intensive care (Second Edition). Philadelphia: W.B. Saunders; 2010. p. 106-9.

10. Cubedo J, Blasco A, Padro T, Ramaiola I, Juan-Babot O, Goicolea J, et al. Molecular signature of coronary stent thrombosis: oxidative stress and innate immunity cells. Thromb Haemost. 2017;117(9):1816-27.

11. Barrett T, Wilhite SE, Ledoux P, Evangelista C, Kim IF, Tomashevsky M, et al. NCBI GEO: archive for functional genomics data sets-update. Nucleic Acids Res. 2012;41(D1):D991-D5.

12. Szklarczyk D, Franceschini A, Wyder S, Forslund K, Heller D, Huerta-Cepas J, et al. STRING V10: protein-protein interaction networks, integrated over the tree of life. Nucleic Acids Res. 2015;43(D1):D447-D52

13. Maciejak A, Kiliszek M, Michalak M, Tulacz D, Opolski G, Matlak K, et al. Gene expression profiling reveals potential prognostic biomarkers associated with the progression of heart failure. Genome Med. 2015;7(1):26.

14. Ritchie ME, Diyagama D, Neilson J, van Laar R, Dobrovic A, Holloway A, et al. Empirical array quality weights in the analysis of microarray data. BMC Bioinformatics. 2006;7:261.

15. Ritchie ME, Phipson B, Wu D, Hu Y, Law CW, Shi W, et al. Limma powers differential expression analyses for RNA-sequencing and microarray studies. Nucleic Acids Res. 2015;43(7):e47.

16. Shannon P. Cytoscape: a software environment for integrated models of biomolecular interaction networks. Genome Res. 2003;13(11):2498-504.

17. Flentje A, Kalsi R, Monahan TS. Small GTPases and their role in vascular disease. Int J Mol Sci. 2019;20(4):E917.

18. López-Sendón J, Gurfinkel EP, Lopez de Sa E, Agnelli G, Gore JM, Steg PG, et al. Factors related to heart rupture in acute coronary syndromes in the global registry of acute coronary events. Eur Heart J. 2010;31(12):1449-56.

19. Eitel I, Gehmlich D, Amer O, Wohrle J, Kerber S, Lauer B, et al. Prognostic relevance of papillary muscle infarction in reperfused infarction as visualized by cardiovascular magnetic resonance. Circ Cardiovasc Imaging. 2013;6(6):890-8.

20. Doimo S, Fabris E, Chiapolino S, Barbati G, Priolo L, Korcova R, et al. Prognostic role of left ventricular dysfunction in patients with coronary artery disease after an ambulatory cardiac rehabilitation program. Am J Cardiol. 2019;124(3):355-61

21. Al Chekakie MO. Traditional heart failure medications and sudden cardiac death prevention: a review. J Cardiovasc Pharmacol Ther. 2013;18(5):412-26.

22. Zhang TT, Takimoto K, Stewart AF, Zhu C, Levitan ES. Independent regulation of cardiac Kv4.3 potassium channel expression by angiotensin II and phenylephrine. Circ Res. 2001;88(5):476-82.

23. McIntosh MA, Cobbe SM, Kane KA, Rankin AC. Action potential prolongation and potassium currents in left-ventricular myocytes isolated from hypertrophied rabbit hearts. J Mol Cell Cardiol. 1998;30(1):43-53.

24. Gonzalez-Villalobos RA, Shen XZ, Bernstein EA, Janjulia T, Taylor B, Giani JF, et al. Rediscovering ACE: novel insights into the many roles of the angiotensin-converting enzyme. J Mol Med (Berl). 2013;91(10):1143-54

25. Tham DM, Martin-McNulty B, Wang YX, Wilson DW, Vergona R, Sullivan ME, et al. Angiotensin II is associated with activation of NF-kappaB-mediated genes and downregulation of PPARs. Physiol Genomics. 2002;11(1):21-30.

26. Dzau VJ, Bernstein K, Celermajer D, Cohen J, Dahlöf B, Deanfield J, et al. The relevance of tissue angiotensin-converting enzyme: manifestations in mechanistic and endpoint data. Am J Cardiol. 2001;88(9A):1L-20L.

27. Manfrini O, Morrell C, Das R, Barth JH, Hall AS, Gale CP, et al. Effects of angiotensin-converting enzyme inhibitors and beta blockers on clinical outcomes in patients with and without coronary artery obstructions at angiography (from a register-based cohort study on acute coronary syndromes). Am J Cardiol. 2014;113(10):1628-33.

28. Ozaki Y, Imanishi T, Teraguchi I, Nishiguchi T, Orii M, Shiono Y, et al. Association between P-selectin glycoprotein ligand-1 and pathogenesis in acute coronary syndrome assessed by optical coherence tomography. Atherosclerosis. 2014;233(2):697-703.

29. Kappelmayer J, Nagy B Jr. The interaction of selectins and PSGL-1 as a key component in thrombus formation and cancer progression. Biomed Res Int. 2017;2017:6138145.

30. Kitamura K, Sato K, Sawabe M, Yoshida M, Hagiwara N. P-selectin glycoprotein ligand-1 (PSGL-1) expressing CD4 T cells contribute plaque instability in acute coronary syndrome. Circ J. 2018;82(8):2128-35.
31. Fang $H$, Lin J, Wang L, Xie P, Wang X, Fu J, et al. Kruppel-like factor 2 regulates dendritic cell activation in patients with acute coronary syndrome. Cell Physiol Biochem. 2013;32(4):931-41.

32. Niu N, Xu S, Xu Y, Little PJ, Jin ZG. Targeting mechanosensitive transcription factors in atherosclerosis. Trends Pharmacol Sci. 2019;40(4):253-66.

33. Zhao Y, Sun Y. The FBW7-KLF2 axis regulates endothelial functions. Cell Res. 2013;23(6):741-3.

34. Khan S, Phulukdaree A, Ramkaran P, Moodley D, Chuturgoon AA. The Arg72 variant of the $p 53$ functional polymorphism (rs1042522) is associated with coronary artery disease in young south Africans of Indian ancestry. Gene. 2016;593(2):261-4.

35. Saccucci P, Banci M, Amante A, Bottini E, Gloria-Bottini F. Coronary artery disease: evidence of interaction between PTPN22 and p53 genetic polymorphisms. Cardiology. 2011;120(3):166-8.

36. Kolovou V, Tsipis A, Mihas C, Katsiki N, Vartela V, Koutelou M, et al. Tumor protein p53 (TP53) gene and left main coronary artery disease. Angiology. 2018:69(8):730-5.

37. Li JH, Pober JS. The cathepsin B death pathway contributes to TNF plus IFNgamma-mediated human endothelial injury. J Immunol. 2005;175(3):1858-66,

38. Fuchs SY, Adler V, Pincus MR, Ronai Z. MEKK1/JNK signaling stabilizes and activates p53. P Natl Acad Sci USA. 1998;95(18):10541-6.

39. Kienesberger PC, Oberer M, Lass A, Zechner R. Mammalian patatin domain containing proteins: a family with diverse lipolytic activities involved in multiple biological functions. J Lipid Res. 2009;50(Supplement):S63-SS8.

40. Baulande S, Langlois C. Proteins sharing PNPLA domain, a new family of enzymes regulating lipid metabolism. Med Sci (Paris). 2010;26(2):177-84.

41. Pulido MR, Diaz-Ruiz A, Jimenez-Gomez Y, Garcia-Navarro S, Gracia-Navarro $\mathrm{F}$, Tinahones $\mathrm{F}$, et al. Rab18 dynamics in adipocytes in relation to lipogenesis, lipolysis and obesity. PLoS One. 2011;6(7):e22931.

42. Passos-Silva DG, Verano-Braga T, Santos RA. Angiotensin-(1-7): beyond the cardio-renal actions. Clin Sci (Lond). 2013;124(7):443-56.

43. Gay A, Towler DA. Wnt signaling in cardiovascular disease. Curr Opin Lipidol. 2017;28(5):387-96.

44. Fu WB, Wang WE, Zeng CY. Wnt signaling pathways in myocardial infarction and the therapeutic effects of Wnt pathway inhibitors. Acta Pharmacol Sin. 2018;40(1):9-12.

45. Stylianidis V, Hermans KCM, Blankesteijn WM. Wnt signaling in cardiac remodeling and heart failure. Handb Exp Pharmacol. 2017;243:371-93.

46. Haybar H, Khodadi E, Shahrabi S. Wnt/ $\beta$-catenin in ischemic myocardium: interactions and signaling pathways as a therapeutic target. Heart Fail Rev. 2019;24(3):411-9.

47. Rajendran P, Rengarajan T, Thangavel J, Nishigaki Y, Sakthisekaran D, Sethi $\mathrm{G}$, et al. The vascular endothelium and human diseases. Int J Biol Sci. 2013; 9(10):1057-69.

48. Tzima E. Role of small GTPases in endothelial cytoskeletal dynamics and the shear stress response. Circ Res. 2006;98(2):176-85.

49. Rahnamoun H, Hong J, Sun Z, Lee J, Lu H, Lauberth SM. Mutant p53 regulates enhancer-associated H3K4 monomethylation through interactions with the methyltransferase MLL4. J Biol Chem. 2018;293(34):13234-46.

50. Mattera L, Courilleau C, Legube G, Ueda T, Fukunaga R, Chevillard-Briet M, et al. The E1A-associated p400 protein modulates cell fate decisions by the regulation of ROS homeostasis. PLoS Genet. 2010;6(6):e1000983.

51. Bao Y, Lin C, Ren J, Liu J. MicroRNA-384-5p regulates ischemia-induced cardioprotection by targeting phosphatidylinositol-4,5-bisphosphate 3kinase, catalytic subunit delta (PI3K p110delta). Apoptosis. 2013;18(3):260-70.

52. Xiao LI, Cao Y, Wang Y, Lai X, Gao KQ, Du P, et al. Aberrant histone modifications of global histone and MCP-1 promoter in CD14(+) monocytes from patients with coronary artery disease. Pharmazie. 2018;73(4):202-6.

53. Sugawara T, Kano F, Murata M. Rab2A is a pivotal switch protein that promotes either secretion or ER-associated degradation of (pro) insulin in insulin-secreting cells. Sci Rep. 2014;4:6952.

54. Ding $X$, Jiang $X$, Tian $R$, Zhao $P$, Li L, Wang $X$, et al. RAB2 regulates the formation of autophagosome and autolysosome in mammalian cells. Autophagy. 2019:1-13.

55. Aleidi SM, Howe V, Sharpe LJ, Yang A, Rao G, Brown AJ, et al. The E3 ubiquitin ligases, HUWE1 and NEDD4-1, are involved in the posttranslational regulation of the ABCG1 and ABCG4 lipid transporters. J Biol Chem. 2015;290(40):24604-13.

56. Senis YA, Atkinson BT, Pearce AC, Wonerow P, Auger JM, Okkenhaug K, et al. Role of the p1108 PI 3-kinase in integrin and ITAM receptor signalling in platelets. Platelets. 2009;16(3-4):191-202. 
57. Rossello X, Riquelme JA, Davidson SM, Yellon DM. Role of PI3K in myocardial ischaemic preconditioning: mapping pro-survival cascades at the trigger phase and at reperfusion. J Cell Mol Med. 2018;22(2):926-35.

58. Reho JJ, Guo DF, Rahmouni K. Mechanistic target of rapamycin complex 1 signaling modulates vascular endothelial function through reactive oxygen species. J Am Heart Assoc. 2019;8(9):e010662.

\section{Publisher's Note}

Springer Nature remains neutral with regard to jurisdictional claims in published maps and institutional affiliations.

Ready to submit your research? Choose BMC and benefit from:

- fast, convenient online submission

- thorough peer review by experienced researchers in your field

- rapid publication on acceptance

- support for research data, including large and complex data types

- gold Open Access which fosters wider collaboration and increased citations

- maximum visibility for your research: over $100 \mathrm{M}$ website views per year

At $\mathrm{BMC}$, research is always in progress.

Learn more biomedcentral.com/submissions 